\title{
ECOLOGICAL STUDIES ON THE POLYMORPHIC LADYBIRD ADALIA BIPUNCTATA IN THE NETHERLANDS. II. POPULATION DYNAMICS, DIFFERENTIAL TIMING OF REPRODUCTION AND THERMAL MELANISM
}

\author{
BY PAUL M. BRAKEFIELD*
}

\begin{abstract}
Department of Population and Evolutionary Biology, University of Utrecht, Padualaan 8 , Utrecht, The Netherlands
\end{abstract}

\section{SUMMARY}

(1) Evidence was sought for the relevance of the theory of thermal melanism to the dynamics of polymorphism in Adalia bipunctata in the Netherlands.

(2) A mark-release-recapture experiment performed from April to October 1980 found no difference in length of dispersal or rate of loss between melanics and non-melanics consistent with an influence of thermal melanism on activity. However, comparisons of melanic frequencies in five populations indicated that melanics tend to disperse earlier in May from shrubs to adjacent trees than non-melanics. Inspection of all data suggests that the mean dispersal length of c. $20 \mathrm{~m}$ is a considerable underestimate of the mean migration length of offspring about parent's birthplace.

(3) Sequential samples from twelve sites with differing melanic frequencies showed that melanics tend to emerge earlier from pupae than non-melanics. The time lag ( $\pm 95 \%$ C.L.) between the estimated peaks in emergence was $1.79 \pm 0.74$ days in 1980 and $0.76 \pm 0.71$ days in 1981 with an emergence period of c. 31 days.

(4) Melanics in post-hibernation populations tend to mate, oviposit and die earlier than non-melanics.

(5) This study supports the hypothesis that thermal melanism through an influence on activity results in an earlier reproduction of melanics.

(6) It is suggested that changes in relative fitness relationships associated with clines within the study area involve interactions between climate, thermal melanism and life cycle parameters of both the ladybird and its aphid prey. Selective predation may also influence the polymorphism.

(7) The differential timing of adult eclosion may contribute to the maintenance of the polymorphism.

\section{INTRODUCTION}

Melanism in the two-spot ladybird beetle Adalia bipunctata (L.) has been extensively studied by population geneticists. A number of theories have been advanced to account for patterns of geographical variation (see review by Muggleton 1978). The polymorphism must have a different selective basis to those of industrial melanism in some species of moths such as Biston betularia (see Lees 1981) since A. bipunctata is warningly-coloured

\footnotetext{
* Present address: Department of Biological Sciences, University of Exeter, Perry Road, Exeter EX 4 4QG.
} 
and metabolizes an alkoloid, adaline, which is repellant or distasteful to at least some vertebrate and invertebrate predators (Frazer \& Rothschild 1960; Pasteels et al. 1973; Tursch et al. 1973). Melanic specimens of A. bipunctata in collections date back to the late seventeenth century (Hammond 1975). In Britain and in the Netherlands there are negative correlations between hours of bright sunshine and the frequency of melanics (Muggleton, Lonsdale \& Benham 1975; Brakefield 1984a). This relationship is consistent with the theory of thermal melanism which predicts that melanic beetles are favoured in conditions of low sunshine because of a more efficient absorption of solar radiation (Lusis 1961; Benham, Lonsdale \& Muggleton 1974; Muggleton, Lonsdale \& Benham 1975; Brakefield \& Willmer 1984). However, the causal nature of such statistical relationships must be tested and direct evidence from natural populations for the theory is lacking.

This paper reports the results of a multiple capture-recapture experiment performed to detect any difference in dispersal rate between the morph classes arising from differences in the intensity or duration of adult activity associated with thermal melanism. Differences of this type have been demonstrated in alpine Colias butterflies (Roland 1982). Analysis of the capture-recapture data also gives estimates of basic population parameters such as survival rate. The relevance of the theory of thermal melanism to the dynamics of the polymorphism in $A$. bipunctata is investigated by sequential sampling of adult and pupal populations at sites along the clines in the Netherlands described by Brakefield (1984a).

\section{METHODS}

The seventy-five study sites are described by Brakefield (1984a). Most of them (numbers 1-57) were on four transects of 90 or $120 \mathrm{~km}$ in length; two running eastwards from the coast of central Holland and two bisecting these from north to south. The transects traversed an area between a region of low, and one of high melanic frequency (Brakefield 1984a, Figs 6 \& 7).

Thirteen sites from the transects were selected for collection of sequential samples of adults and of prepupae and pupae in 1980 and 1981. Samples were usually obtained from a number of different habitats at each site. Details of the sampling methods and the population biology of $A$. bipunctata at the study sites are given by Brakefield (1984a). In this paper the data for the quadrimaculata and sexpustulata melanic morphs are combined to give a single melanic class. The non-melanic morph is typica.

\section{Analysis of sequential data}

Many of the data sets handled involve the factors of site or habitat, time and frequency. Analyses of the resulting three-way contingency tables are based upon log-linear models following the method given by Sokal \& Rohlf (1981, pp. 747-765). A $G$-value for the three-way interaction is established by use of an iterative proportional fitting algorithm. $G$-values for two-way interactions are obtained following calculation of the expected frequencies. The significance of each two-way interaction is then examined by computing the $G$-statistic for goodness of fit from the difference between the $G$-values of the models for the three-way and the relevant two-way interactions. Each then represents the decrease in fit of expected and observed values due to one of the two-way terms being dropped from the model. 


\section{The capture-recapture experiment}

A capture-recapture experiment was performed at De Uithof (site 12) during the spring to autumn period of adult activity in 1980 . Releases of marked beetles were made on thirty occasions at approximately 6-day intervals (mean \pm S.D. $=5.90 \pm 1.52$ days). The data analysis assumes that all intervals were of 6 days. Date-specific marks were applied to cooled insects using Talens hobby color universal paint. At least $24 \mathrm{~h}$ at $4{ }^{\circ} \mathrm{C}$ was allowed for the paint to dry prior to release. The beetles are inactive at this temperature so that the paint is not smeared. Marks were not always permanent but the rate of loss was low for beetles kept outdoors in large cylindrical net cages (Table 1). Collections of $A$. bipunctata from a number of remote and local study sites were used in the experiment. Details of the numbers and phenotype of beetles released and captured in consecutive periods of the experiment are given in Table 2. Similar numbers of non-melanics and melanics were released. All releases were made at a central point on a habitat site. Shrubs or trees were searched in a consistent way from one sampling occasion to another.

\section{RESULTS}

\section{Population dynamics}

The area searched in the capture-recapture experiment is shown in Fig. 1. The first four groups of releases were made at a point on an established planting of Crataegus monogyna. After emigration of nearly all $\boldsymbol{A}$. bipunctata had occurred, releases were made at a central tree on a grid of three rows of seventy-seven Tilia europaea which were 32 years old (and see Table 2). Three small groups of Tilia were included in the search area. These plants provided favourable breeding habitats since numbers of pupae were collected (Crataegus: $n=43, \%$ melanics $=32 \cdot 56$; all Tilia $: n=260,25 \cdot 67 \%)$.

\section{Adult movement}

The distribution of recaptures is shown in Fig. 1. Table 3 indicates that marked beetles tended to disperse further in the middle periods $(2-4)$ of the experiment. There is a significant difference between movements in this period and those in the first and the last ( $U=7039$ and 7233.5 , respectively with $P<0.001$ ). There is also evidence of a lower recapture rate in the middle period (Table 2 , overall $G=17.60 ; P<0.001$ ). The early release period on Crataegus was associated with cooler temperatures and the last with a high proportion of recently eclosed beetles in releases (Table 2). The increase in observed mean distance moved on the Tilia grid with time from release during the middle period of the experiment is similar to that predicted from a random diffusion model where the constant step length is defined as the distance traversed between release and first subsequent sampling occasion (Fig. 2). This occurs even though the proportion of each annulus which is covered by trees declines markedly with distance from release (see Fig. 1). These observations suggest that random trivial flights (Southwood 1962) which are tens

TABLE 1. Proportion of marks lost in successive time periods for a cohort of captive Adalia bipunctata

\begin{tabular}{|c|c|c|c|c|c|c|c|c|}
\hline & 0 & 6 & 12 & 18 & $\begin{array}{c}\text { Time (days) } \\
24\end{array}$ & 30 & 36 & 42 \\
\hline $\begin{array}{l}\text { Number of marks 'alive' } \\
\text { Number of marks lost } \\
\text { Proportion of marks lost }(\%)\end{array}$ & $\frac{374}{-}$ & $\begin{array}{r}318 \\
4 \\
1 \cdot 24\end{array}$ & $\begin{array}{l}292 \\
2 \\
0.68\end{array}$ & $\begin{array}{r}224 \\
12 \\
5 \cdot 08\end{array}$ & $\begin{array}{r}163 \\
8 \\
4 \cdot 68\end{array}$ & $\begin{array}{l}42 \\
6 \\
12 \cdot 50\end{array}$ & $\begin{array}{l}22 \\
2 \\
8 \cdot 33\end{array}$ & $\begin{array}{r}19 \\
0 \\
0\end{array}$ \\
\hline
\end{tabular}




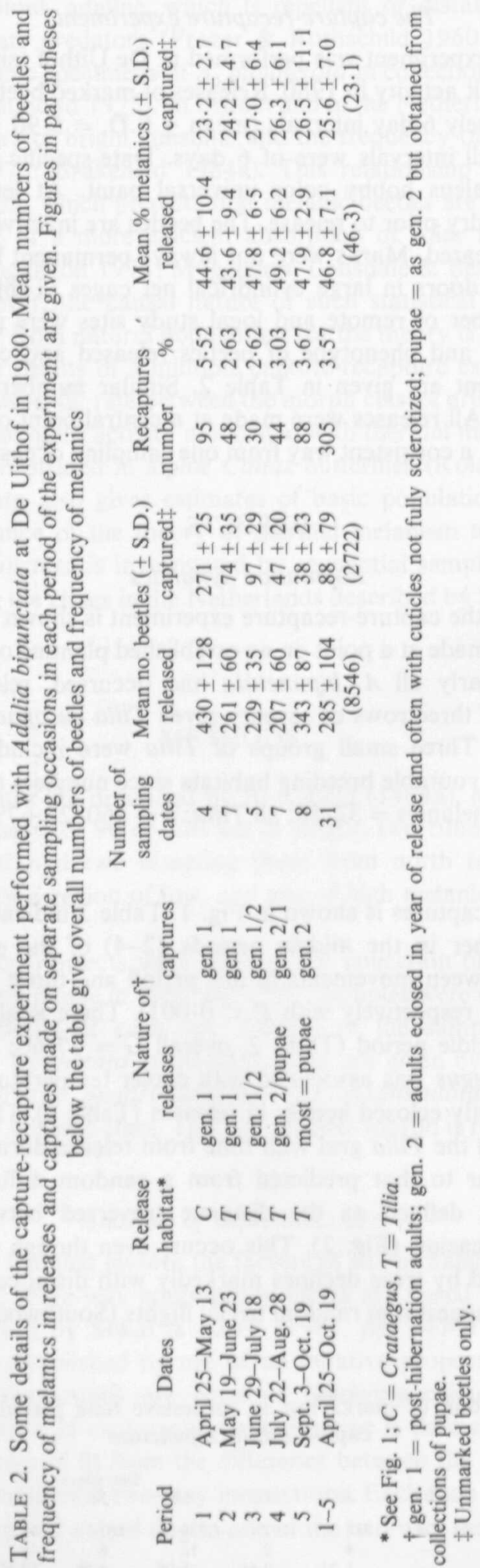




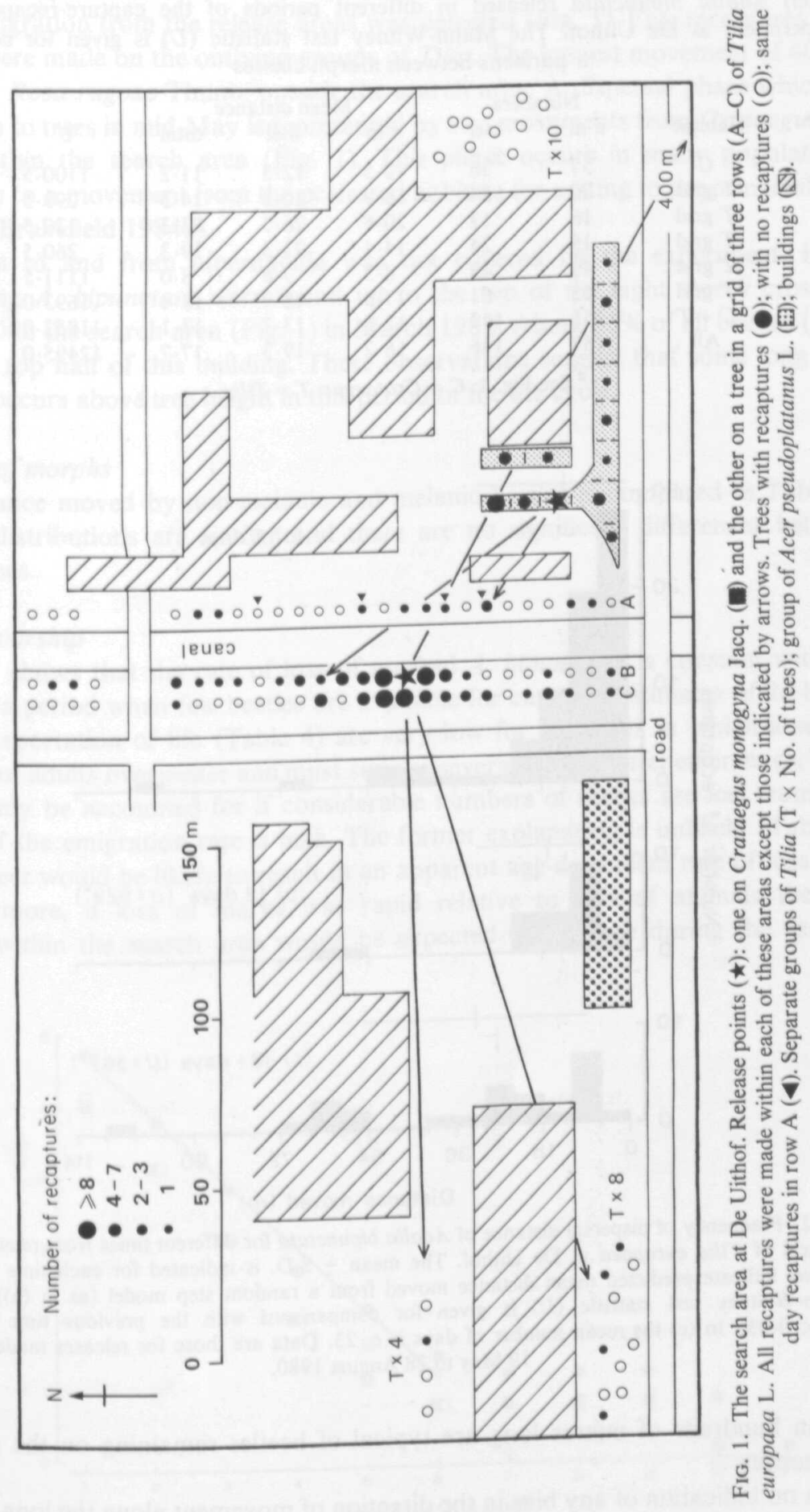


TABLE 3. The mean distance moved in metres by non-melanic $(n-m)$ and melanic (mel) Adalia bipunctata released in different periods of the capture-recapture experiment at De Uithof. The Mann-Witney test statistic $(U)$ is given for comparisons between morph classes

\begin{tabular}{|c|c|c|c|c|c|c|c|c|}
\hline \multirow[b]{2}{*}{ Period* } & \multirow[b]{2}{*}{ Habitat* } & \multicolumn{2}{|c|}{ Numbers } & \multicolumn{3}{|c|}{ Mean distance } & \multirow[b]{2}{*}{$U$} & \multirow[b]{2}{*}{$P$} \\
\hline & & $\mathrm{n}-\mathrm{m}$ & mel & $n-m$ & mel & total & & \\
\hline 1 & C & 57 & 36 & $10 \cdot 5$ & $12 \cdot 3$ & 11.2 & $1100 \cdot 5$ & N.S. \\
\hline 2 & $T$ grid & 20 & 24 & 18.9 & 10.5 & $14 \cdot 3$ & 293.5 & N.S. \\
\hline 3 & $T$ grid & 16 & 13 & $20 \cdot 6$ & $26 \cdot 5$ & $23 \cdot 3$ & $120 \cdot 5$ & N.S. \\
\hline 4 & $T$ grid & 19 & 24 & 14.4 & $23 \cdot 3$ & $19 \cdot 3$ & $260 \cdot 5$ & N.S. \\
\hline 5 & $T$ grid & 43 & 45 & $8 \cdot 3$ & 7.8 & 8.0 & 1111.5 & N.S. \\
\hline $2-4$ & $T$ grid & 55 & 61 & 17.8 & 18.9 & $18 \cdot 4$ & 1693.0 & N.S. \\
\hline $1-5$ & $C+T$ & 155 & 142 & 12.5 & 13.7 & 13.1 & $11852 \cdot 0$ & N.S. \\
\hline $1-5$ & All & 159 & 146 & $16 \cdot 2$ & $19 \cdot 3$ & 17.7 & 12495.0 & N.S. \\
\hline
\end{tabular}

* See Fig. $1 ; C=$ Crataegus, $T=$ Tilia.

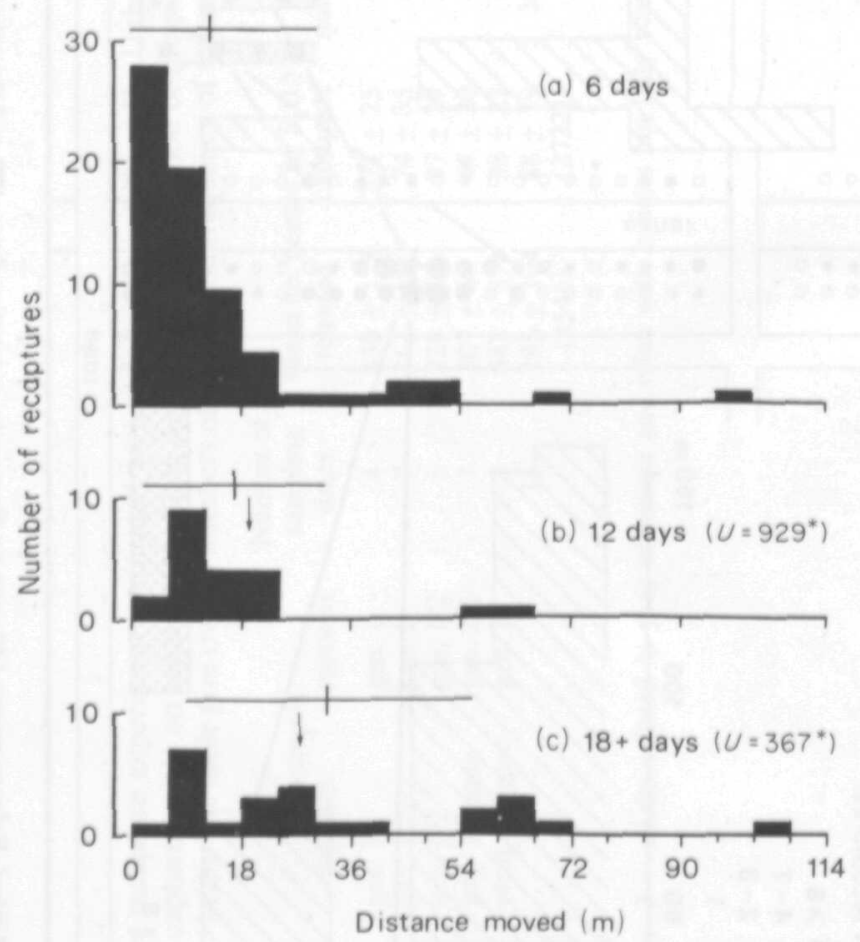

FiG. 2. Frequency of dispersal distance of Adalia bipunctata for different times from release on the grid of Tilia europaea at De Uithof. The mean \pm S.D. is indicated for each time class. Arrows indicate predicted mean distance moved from a random step model (as in (a)). The Mann-Whitney test statistic $(U)$ is given for comparisons with the previous time class $\left({ }^{*} P<0.05\right)$. In (c) the mean number of days is c. 23. Data are those for releases made from 19 May to 28 August 1980.

rather than hundreds of metres long are typical of beetles remaining on the grid in the summer months.

There is no indication of any bias in the direction of movement along the long axis of the Tilia grid. The longer range same-day recaptures made on row A (Fig. 1) were taken downwind from the release tree on days of low wind speed. 
Some emigration from the release areas was detected (Fig. 1). Five recaptures from the Tilia grid were made on the outlying groups of Tilia. The longest movement of $400 \mathrm{~m}$ was recorded to Rosa rugosa Thunb. outside the search area. A dispersal phase which occurs from shrubs to trees in mid-May is represented by two movements from Crataegus to Tilia detected within the search area (Fig. 1). This phase occurs in many populations and corresponds to a movement from the preferred habitats for mating to the principal ones for egg laying (Brakefield 1984a).

Migration to and from hibernacula was not covered by the experiment. However, overwintering $A$. bipunctata were found up to the top of the eight storey cross-shaped building within the search area (Fig. 1) in March 1982. About $25 \%$ of all beetles $(n=610)$ were in the top half of this building. These observations suggest that some long distance movement occurs above tree height in this period of the life cycle.

\section{Movement of morphs}

The distance moved by non-melanic and melanic beetles is compared in Table 3. The frequency distributions are similar and there are no significant differences between the morph classes.

\section{Adult survivorship}

Figure 3 shows that the rate of loss of marked A. bipunctata is constant with time at least up to a period when few beetles are available for capture. Estimates of 24-h survival rates and expectation of life (Table 4) are very low for a species in which a substantial proportion of adults overwinter and must survive several months after emergence. They can therefore only be accounted for if considerable numbers of marks are lost from released beetles or if the emigration rate is high. The former explanation is unlikely (Table 1) and such an effect would be likely to result in an apparent age-dependent rate of loss (see Fig. 3). Furthermore, if loss of marks was rapid relative to loss of animals the melanic frequency within the search area would be expected to increase during the experiment.

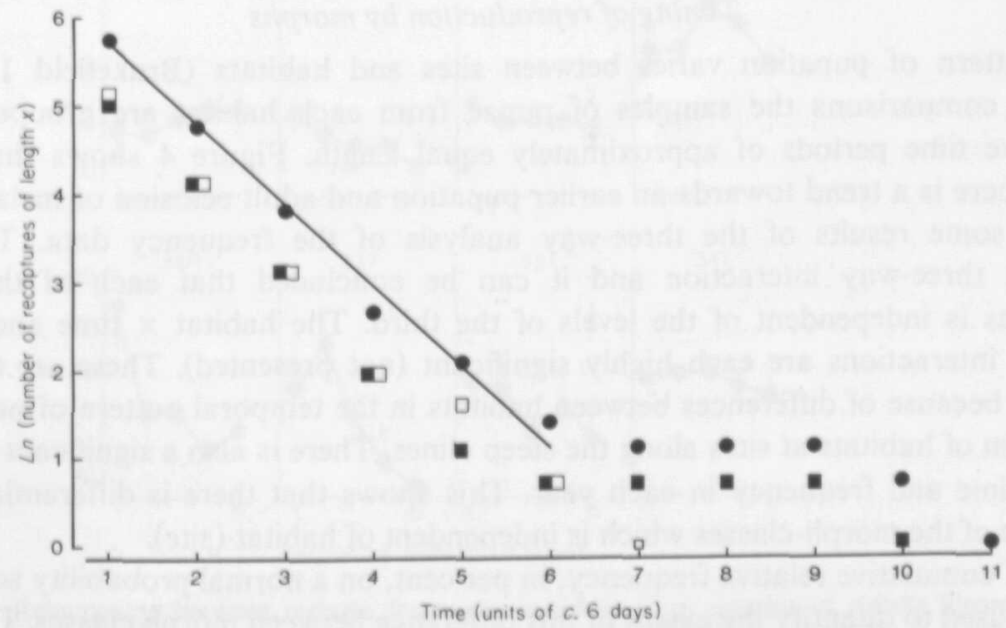

F1G. 3. Natural logarithm of number of released Adalia bipunctata known to have survived for the indicated number of intersampling periods at De Uithof in 1980. The line is fitted by eye through the points for total beetles which approximate to a period of constant survival. ( $\square$ ), Non-melanics; ( $\mathbf{m})$, melanics. 
TABLE 4. Estimates of 24-h survival rate, expectation of life and mean 'daily' population size obtained by analysis of the multiple capture-recapture data for Adalia bipunctata

\begin{tabular}{lccc}
$\begin{array}{c}\text { Method of } \\
\text { analysis }\end{array}$ & $\begin{array}{c}24-\mathrm{h} \\
\text { survival } \\
\text { rate }\end{array}$ & $\begin{array}{c}\text { Expectation } \\
\text { of life } \\
\text { (days) }\end{array}$ & $\begin{array}{c}\text { Mean } \\
\text { population } \\
\text { size }( \pm \text { S.E. })\end{array}$ \\
$\begin{array}{l}\text { Fisher-Ford } \\
\text { Jolly }\end{array}$ & 0.876 & 7.55 & $3465 \pm 499$ \\
Seber & $0.871^{*}$ & 7.24 & $4100 \pm 694$ \\
\hline & $0.857^{+}$ & 6.48 & -
\end{tabular}

* Obtained using a geometric mean of 'daily' estimates.

† Estimated from the slope of the line fitted in Fig. 3.

There is little indication of this (Table 2; and see for pupae above). Therefore the estimates in Table 4 suggest a high rate of emigration from the search area. The estimates of daily population size included in Table 4 will then be overestimates.

\section{Survivorship of morphs}

Figure 3 shows a similar rate of loss for marked non-melanic and melanic beetles. The data plotted in Fig. 3 analysed by Manly's (1973) method give an estimate ( \pm S.E.) of the selective value $(w)$ of melanics compared to non-melanics $(w=1)$ of $1.038 \pm 0.057$. The selective advantage is not significant $(t=0.67)$. Recapture rates for the morph classes are similar (see Tables $2 \& 3$; overall $G=0 \cdot 29, P>0 \cdot 1$ ).

Two selective predation experiments using dead frozen A. bipunctata glued to leaves (cf. Muggleton 1978) were performed in June 1980 at sites 23 and 24 in shrub habitats where the species were abundant. $5.9 \%(n=11)$ of all beetles disappeared over $24 \mathrm{~h}$. In one experiment on Rosa rugosa none of 104 beetles were taken. Some losses in the other experiment on mixed shrubs may have resulted from brushing together of vegetation because of wind. Beetles were exposed in pairs with one of each morph class separated by c. $25 \mathrm{~cm}$. There was no evidence of selective predation $(G=0 \cdot 10$, d.f. $=1, P>0 \cdot 1)$.

\section{Timing of reproduction by morphs}

The pattern of pupation varies between sites and habitats (Brakefield 1984a). For statistical comparisons the samples of pupae from each habitat are grouped into five consecutive time periods of approximately equal length. Figure 4 shows that at many habitats there is a trend towards an earlier pupation and adult eclosion of melanics. Table 5a gives some results of the three-way analysis of the frequency data. There is no significant three-way interaction and it can be concluded that each of the two-way interactions is independent of the levels of the third. The habitat $\times$ time and habitat $x$ frequency interactions are each highly significant (not presented). These are trivial since they arise because of differences between habitats in the temporal pattern of pupation and the location of habitats at sites along the steep clines. There is also a significant association between time and frequency in each year. This shows that there is differential timing of emergence of the morph-classes which is independent of habitat (site).

Plots of cumulative relative frequency, in per cent, on a normal probability scale against date were used to quantify the extent of this difference between morph classes. They did not indicate any substantial departures from normality. The date by which $50 \%$ of each morph class had pupated in each habitat was estimated (see Cassie 1954). The mean number of days $( \pm 95 \%$ C.L.) by which this date for melanics preceded that for non-melanics was 

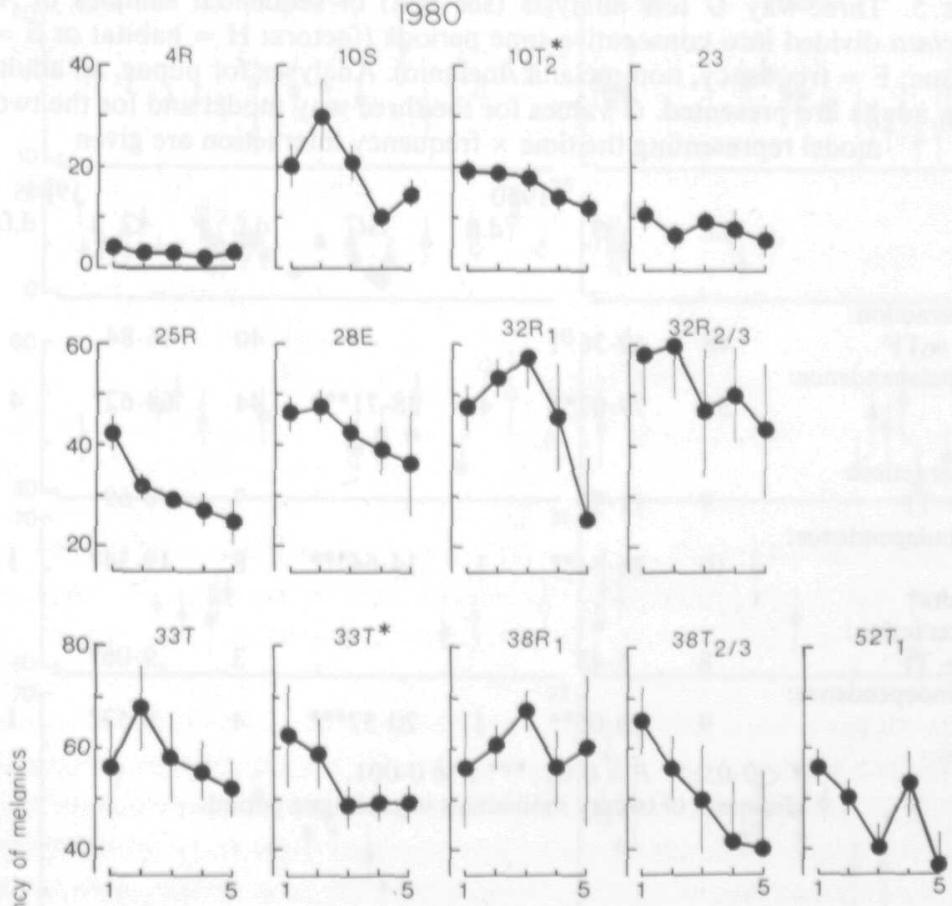

1981
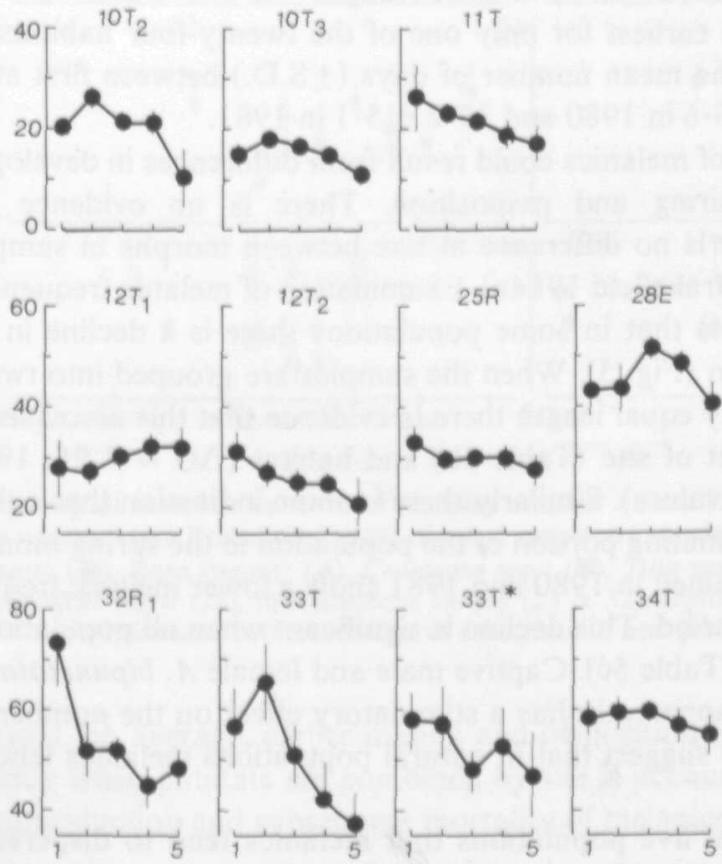

Sequential samples of pupae

F1G. 4. Relationship between melanic frequency in adults from samples of Adalia bipunctata pupae and time of collection. The site number and habitat are indicated: R, Rosa rugosa; S, Salix spp.; T, Tilia spp.; E, Sambucus nigra (L.). Vertical ranges show standard errors. *Second generation (see Brakefield 1984a). 
TABLE 5. Three-way $G$ test analysis (see text) of sequential samples of Adalia bipunctata divided into consecutive time periods (factors: $\mathrm{H}=$ habitat or $\mathrm{S}=$ site; $\mathrm{T}=$ time; $\mathrm{F}=$ frequency, non-melanic/melanic). Analyses for pupae, all adults and mating adults are presented. $G$ values for the three-way model and for the two-way model representing the time $x$ frequency interaction are given

\begin{tabular}{|c|c|c|c|c|c|c|c|c|}
\hline & \multicolumn{4}{|c|}{1980} & \multicolumn{4}{|c|}{1981} \\
\hline Model & d.f. & $G$ & d.f. & $\Delta G$ & d.f. & $G$ & d.f. & $\Delta G$ \\
\hline \multicolumn{9}{|l|}{ (a) Pupae } \\
\hline $\mathrm{HT}+\mathrm{HF}+\mathrm{TF}$ & 48 & $40 \cdot 36$ & & & 40 & $46 \cdot 84$ & & \\
\hline $\begin{array}{l}\text { Conditional independence: } \\
\mathrm{HT}+\mathrm{HF}\end{array}$ & & & & & & & & \\
\hline $\begin{array}{l}\mathrm{HT}+\mathrm{HF} \\
\text { (b) All adults }\end{array}$ & 52 & $79.07^{* *}$ & 4 & $38.71^{* * * *}$ & 44 & $64.62^{*}$ & 4 & $17 \cdot 78^{* *}$ \\
\hline $\begin{array}{l}\text { (b) All adults } \\
\text { Complete interaction: }\end{array}$ & & . & & & & & & \\
\hline $\mathrm{ST}+\mathrm{SF}+\mathrm{TF}$ & 9 & 11.90 & & & 7 & 6.69 & & \\
\hline Conditional independence: & & & & & & & & \\
\hline $\mathrm{ST}+\mathrm{SF}$ & 10 & $26 \cdot 54^{* *}$ & 1 & $14 \cdot 64^{* * *}$ & 8 & $19 \cdot 34^{*}$ & 1 & $12 \cdot 35^{* * *}$ \\
\hline \multirow{2}{*}{\multicolumn{9}{|c|}{$\begin{array}{l}\text { (c) Mating adults }{ }^{\dagger} \\
\text { Complete interaction: }\end{array}$}} \\
\hline Complete interaction: & & & & & & & & \\
\hline $\begin{array}{c}\mathrm{ST}+\mathrm{SF}+\mathrm{TF} \\
\text { Conditional independence: }\end{array}$ & 8 & 5.48 & & & 3 & $9 \cdot 06^{*}$ & & \\
\hline $\mathrm{ST}+\mathrm{SF}$ & 9 & $26 \cdot 05^{* *}$ & 1 & $20 \cdot 57^{* * *}$ & 4 & 9.52* & 1 & 0.45 \\
\hline
\end{tabular}

$1.79 \pm 0.74$ in 1980 and $0.76 \pm 0.71$ in 1981 (ranges $=0.5-5.1$ and $-0.5-4.1$ ). The date for non-melanics was the earliest for only one of the twenty-four habitats. These figures may be compared with the mean number of days $( \pm$ S.D.) between first and last samples from a habitat of $31.3 \pm 6.6$ in 1980 and $31.2 \pm 5.1$ in 1981 .

The earlier emergence of melanics could result from differences in development rate or in the timing of adult pairing and oviposition. There is no evidence for differential development rates. There is no difference in size between morphs in samples of each sex from three populations (Brakefield 1984a). Examination of melanic frequency in successive samples of adults suggests that in some populations there is a decline in frequency with time following hibernation (Fig. 5). When the samples are grouped into two periods (early and late) of approximately equal length there is evidence that this association is significant and that it is independent of site (Table $5 b)$ and habitat $(\Delta G=7.95,1980$; and 14.54, 1981; $P<0.01$ for both values). Similarly there is some indication that a decline occurs in melanic frequency in the mating portion of the population in the spring months. Thus ten of the thirteen data sets obtained in 1980 and 1981 show a lower melanic.frequency in mating animals during the late period. This decline is significant when all populations are analysed in 1980 but not in 1981 (Table 5c). Captive male and female $A$. bipunctata mate a number of times and copulation apparently has a stimulatory effect on the number of eggs laid (in Hodek 1973). My results suggest that in natural populations melanics tend to mate earlier than non-melanics.

There is evidence from five populations that melanics tend to disperse from Rosa or Crataegus shrubs to nearby Tilia trees earlier than non-melanics (Table 6). This is also evident in the pattern of changes in melanic frequency in the sequences of samples obtained on these types of habitat at some sites (Fig. 5, e.g. sites 12, 32/33 and 38). The analysis of population biology suggests that this movement involves an excess of females dispersing to oviposition habitats (Brakefield 1984a). The observations on changes in melanic frequency 

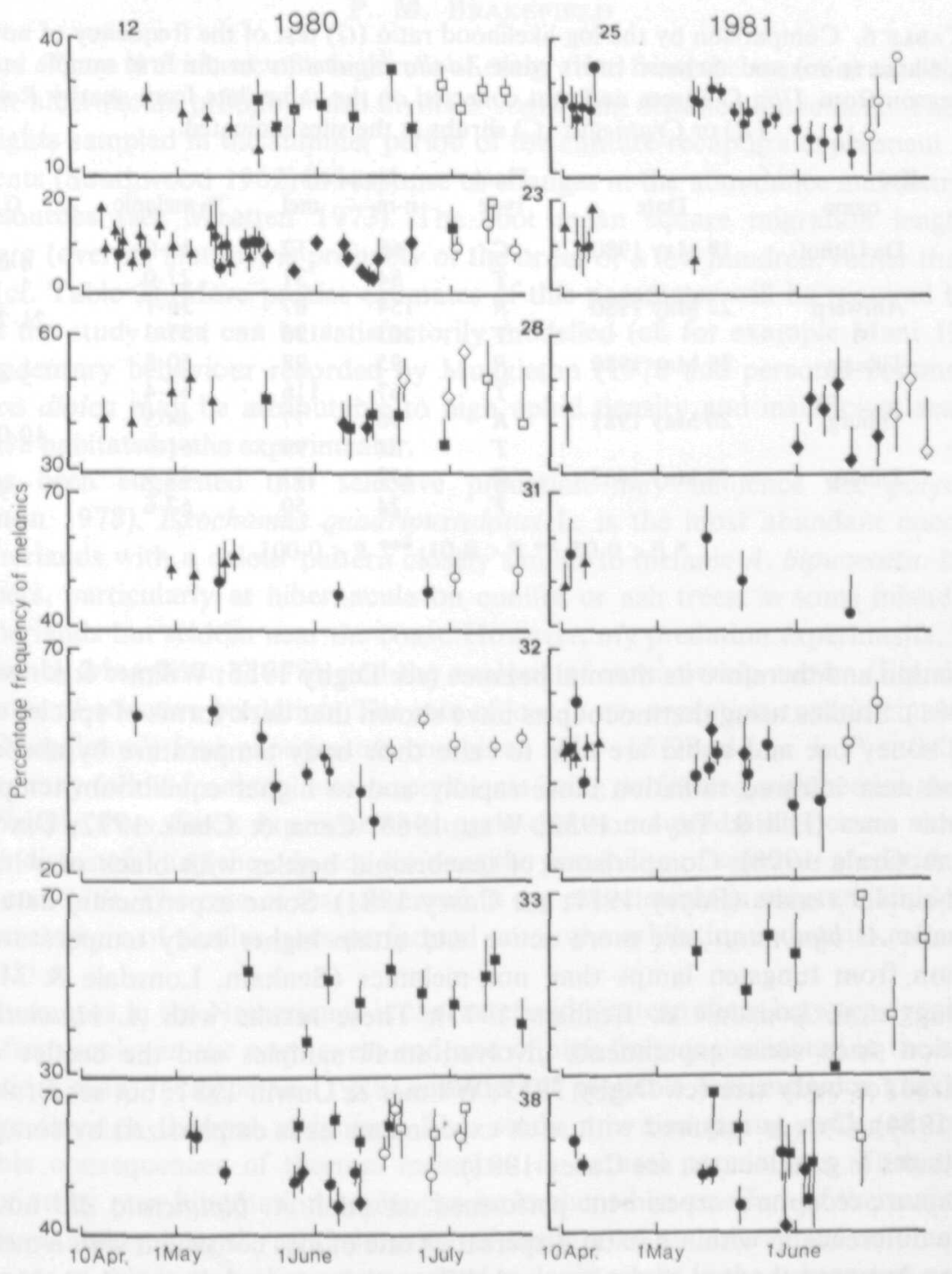

FIG. 5. Frequency of melanics in series of samples of adult Adalia bipunctata from the sites indicated by numbers (see Brakefield 1984a). Vertical ranges are standard errors. Samples from different plants: (๑), Rosa rugosa; (\), Crataegus spp.; (- Tilia spp.; (†), Urtica dioica L. (site 38), Sambucus nigra (28), miscellaneous shrubs (23 \& 32). Open symbols show samples obtained after commencement of emergence of new generation.

in habitats suggest, on average, earlier mating and oviposition by melanics. The decline in melanic frequency when habitats are combined by site is accounted for as an effect of the overall earlier reproduction and subsequent mortality of melanics.

\section{DISCUSSION}

Solar radiation can be an important constraint on daily and seasonal activity of insects (e.g. Roland 1982). The colour of an insect is one factor which influences its absorption of 
TABLE 6. Comparison by the log-likelihood ratio $(G)$ test of the frequency of nonmelanic (n-m) and melanic (mel) adult Adalia bipunctata in the first sample in a season from Tilia $(T)$ trees and that collected on the same date from nearby Rosa

$(R)$ or Crataegus $(C)$ shrubs at the sites indicated.

\begin{tabular}{|c|c|c|c|c|c|c|c|}
\hline \multicolumn{3}{|c|}{ Site } & \multirow{2}{*}{$\begin{array}{l}\text { Plant } \\
\text { type }\end{array}$} & \multicolumn{2}{|c|}{ Numbers } & \multirow[b]{2}{*}{$\%$ melanic } & \multirow[b]{2}{*}{$G_{\text {adj. }}$} \\
\hline no. & name & Date & & $n-m$ & mel & & \\
\hline 12 & De Uithof & 19 May 1980 & $\begin{array}{l}C \\
T\end{array}$ & $\begin{array}{l}68 \\
84\end{array}$ & $\begin{array}{l}12 \\
31\end{array}$ & $\begin{array}{l}15.0 \\
27.0\end{array}$ & $4 \cdot 01^{*}$ \\
\hline 52 & Antwerp & 22 May 1980 & $\begin{array}{l}R \\
T\end{array}$ & $\begin{array}{l}154 \\
103\end{array}$ & $\begin{array}{r}87 \\
138\end{array}$ & $\begin{array}{l}36 \cdot 1 \\
57.3\end{array}$ & $21.78^{* * * *}$ \\
\hline 38 & Tilburg & 28 May 1980 & $\begin{array}{l}R \\
T\end{array}$ & $\begin{array}{l}95 \\
67\end{array}$ & $\begin{array}{r}98 \\
116\end{array}$ & $\begin{array}{l}50 \cdot 8 \\
63.4\end{array}$ & $5.47^{*}$ \\
\hline 38 & Tilburg & 20 May 1981 & $\begin{array}{l}R \\
T\end{array}$ & $\begin{array}{l}96 \\
61\end{array}$ & $\begin{array}{l}77 \\
99\end{array}$ & $\begin{array}{l}44.5 \\
61.9\end{array}$ & $10 \cdot 07^{* *}$ \\
\hline 38 & Tilburg & 14 May 1982 & $\begin{array}{l}R \\
T\end{array}$ & $\begin{array}{r}192 \\
24\end{array}$ & $\begin{array}{r}191 \\
50\end{array}$ & $\begin{array}{l}49 \cdot 9 \\
67 \cdot 6\end{array}$ & $7.91^{* *}$ \\
\hline
\end{tabular}

solar radiation and therefore its thermal balance (see Digby 1955; Willmer \& Unwin 1981; Casey 1981). Studies using thermocouples have shown that dark forms of species of locust, butterfly, honey bee and aphid are able to raise their body temperature by absorption of visible and near infrared radiation more rapidly and to higher equilibrium temperatures than lighter ones (Hill \& Taylor 1933; Watt 1968; Cena \& Clark 1972; Dixon 1972; Douglas \& Grula 1978). Comparisons of tenebrionid beetles with black or white elytra produced similar results (Edney 1971; see Casey 1981). Some experimental data indicate that melanic $A$. bipunctata are more active and attain higher body temperatures under illumination from tungsten lamps than non-melanics (Benham, Lonsdale \& Muggleton 1974; Muggleton, Lonsdale \& Benham 1975). These results with A. bipunctata need confirmation since some experiments involved small samples and the beetles were not standardized for body size (cf. Digby 1955; Willmer \& Unwin 1981; but see Brakefield \& Willmer 1984). Care is required with such experiments as is emphasized by some contradictory results (e.g. in locusts, see Casey 1981).

The capture-recapture experiment performed on adult $A$. bipunctata did not demonstrate any difference in within-habitat dispersal or rate of loss consistent with a mechanistic association between thermal melanism and differential rates of dispersal. Roland (1982) showed a positive influence of greater melanization of the wings of Colias bufferflies in conditions of cooler temperatures and low solar radiation on the duration of flight and feeding behaviour, dispersal and rate of loss in natural populations. Some similar differences are associated with shell colour and banding variation in the snail Cepaea nemoralis (Tilling 1983). The sources of the releases (cf. Bishop, Cook \& Muggleton 1978a) and the mark-release procedure used in the experiment on A. bipunctata introduce errors into the results. Furthermore, the influence of thermal melanism on movement may be too subtle or intermittent to be detected by the rather coarse techniques used. Future work should perhaps examine the activity of individuals or small groups in microhabitats. However, comparisons of samples from differing local habitats at three sites (Table 6) strongly suggest that differences in dispersal behaviour occur and in particular that melanics disperse earlier than non-melanics from shrub to tree habitats.

The data for dispersal of A. bipunctata (Fig. 2, Table 3; see also Banks 1955) can only provide lower limits for the root mean square migration length of offspring around parent's 
birthplace. There is evidence of a high rate of emigration from the search area. Migration to and from hibernacula probably also involves some long distance movement. The majority of the flights sampled in the summer period of the capture-recapture experiment are trivial movements (Southwood 1962) in response to changes in the abundance and distribution of food resources (see Wratten 1973). The root mean square migration length for $A$. bipunctata (over its lifetime) is probably of the order of a few hundred, rather than tens of metres (cf. Table 3). More precise estimates of this parameter will be required before the clines in the study area can be satisfactorily modelled (cf. for example Mani 1982). The highly sedentary behaviour recorded by Muggleton (1978 and personal communication) on Urtica dioica may be attributable to high aphid density and insufficient searching of alternative habitats by the experimenter.

It has been suggested that selective predation may influence the polymorphism (Muggleton 1978). Exochomus quadripustulatus L. is the most abundant coccinellid in the Netherlands with a colour pattern closely similar to melanic A. bipunctata. It is found in numbers, particularly at hibernacula on conifer or ash trees, in some inland areas of the Netherlands but seldom near the coast. However, my predation experiments, like those performed by Muggleton (1978), and the analysis of survivorship curves (Fig. 3) provide no evidence of selective predation. The rate of loss in my predation experiments was lower than in Muggleton's four experiments combined $(G=15 \cdot 78$, d.f. $=1, P<0.001)$. This difference may follow from the latter experiments being performed with beetles glued on the twigs of apple trees. Such experiments suggest that some predation occurs although the species is distasteful and they do not discount the possibility of selective predation (see also Muggleton 1978). The rate of loss observed in my experiments is substantially lower than that characteristic of similar ones performed on moths exhibiting industrial melanism (see Lees 1981).

The study area in the Netherlands is characterized by steep clines between a region of low melanic frequencies in the north-west and one of high frequencies inland in the south-east (Brakefield 1984a). Muggleton (1978) considers it probable that melanics gain a general advantage through thermal melanism. This study provides strong evidence for certain predictable consequences of thermal melanism in natural populations. Thus the earlier reproduction by post-hibernation adults can be explained as an effect of thermal melanism leading to a higher intensity and duration of activity of melanics than non-melanics. A consequence of this is an earlier emergence of melanic adults in the subsequent generation. There is also a general mating advantage to melanics which can be interpreted as a further consequence of differential activity associated with thermal melanism in the study area (Brakefield 1984b). Whilst in the south-east of the Netherlands melanics are favoured through thermal melanism, in the north-west this advantage is outweighed by selection against them by some other factor. The higher levels of spring sunshne in the north-west, which contribute to the negative correlation between hours of sunshine and melanic frequency (Brakefield 1984a), are unlikely to have a direct influence, as for example through producing heat stress in melanics, on the polymorphism. This is supported by the absence of consistent changes in the apparent effects of thermal melanism on reproduction along the clines. Furthermore, high frequencies of melanics are found in some other regions in the species' range with high sunshine (Scali \& Creed 1975; Muggleton 1978).

The observations on population biology (Brakefield 1984a, Fig. 5) suggest that post-hibernation reproduction tends to occur earlier inland in the Netherlands. If this results in a higher chance of a second generation then melanics may gain an advantage over non-melanics through the earlier emergence from pupae. The earlier breeding inland is 
correlated with an earlier increase in spring temperatures; for example a mean daily temperature of $>10^{\circ} \mathrm{C}$ occurs, on average, 10 days earlier inland than on the coast. This will influence the timing of the increase in aphid numbers (e.g. Dixon 1971). These observations suggest that a more complete understanding of selection acting on the polymorphism will necessitate study of spatial variation in the synchronization of the reproduction of the melanic genotypes of Adalia and their aphid prey.

A difference in the timing of adult emergence in natural populations has been detected between the non-melanic and melanic morphs of the moth Odontoptera (= Gonodontis) bidentata (Bishop, Cook \& Muggleton 1978b; Cook \& Jacobs 1983). In this case melanics tend to emerge later than non-melanics and the delay in emergency may amount to $50-75 \%$ of the total emergence period (see Mani 1981). Thus the effect is substantially greater than in A. bipunctata where the delay (for non-melanic homozygotes) is, on average, about $3-6 \%$ of the total emergence period (maximum 15\%). Theoretical studies have shown that delayed emergence in $O$. bidentata may maintain the polymorphism through the introduction of frequency dependent factors (Mani 1981). Under some conditions this can occur even in the absence of heterozygote advantage. Similar consequences may be relevant to A. bipunctata in the Netherlands when differential timing of breeding occurs in the first generation and this is followed by production of a second summer generation. Such consequences will vary geographically with the variation in population biology (Brakefield 1984a). Other factors which have been implicated in the maintenance of the polymorphism are non-random mating (e.g. O'Donald \& Muggleton 1979; Majerus, O’Donald \& Weir 1982) and cyclical selection (Timofeeff-Ressovsky \& Svirezhev 1966; Brakefield 1984b and unpublished).

Experiments carried out since this manuscript went to press have confirmed the basis of thermal melanism in A. bipunctata by demonstrating that melanics have a lower cuticular reflectance and attain higher body temperatures, with more rapid temperature changes, under illumination than non-melanics (Brakefield \& Willmer 1984).

\section{ACKNOWLEDGMENTS}

The main body of this research was carried out on a Royal Society European Exchange Fellowship. I am most grateful to Professor W. Scharloo and members of staff at Utrecht for providing facilities and encouragement. The manuscript was improved by the comments of an anonymous referee. I thank Dr P. Christie for assistance with the three-way contingency analysis and Mrs E. Scarff and Mrs B. Vermeulen who typed the manuscript. Hanke van der Wel abstracted some climatic data from records of the Koninklijk Nederlands Meteorologisch Instituut.

\section{REFERENCES}

Banks, C. J. (1955). An ecological study of coccinellidae (Col.) associated with Alphis fabae Scop. on Vicia faba. Bulletin of Entomological Research, 46, 561-587.

Benham, B. R., Lonsdale, D. \& Muggleton, J. (1974). Is polymorphism in two-spot ladybird an example of non-industrial melanism? Nature (London), 249, 179-180.

Bishop, J. A., Cook, L. M. \& Muggleton, J. (1978a). The response of two species of moths to industrialization in northwest England. II. Relative fitness of morphs and population size. Philosophical Transactions of the Royal Society of London, 281, 517-542.

Bishop, J. A., Cook, L. M. \& Muggleton, J. (1978b). The response of two species of moths to industrialization in northwest England. I. Polymorphisms for melanism. Philosophical Transactions of the Royal Society of London, B, 281, 489-515. 
Brakefield, P. M. (1984a). Ecological studies on the polymorphic ladybird Adalia bipunctata in The Netherlands. I. Population biology and geographical variation of melanism. Journal of Animal Ecology, 53, 761-774.

Brakefield, P. M. (1984b). Selection along clines in the ladybird Adalia bipunctata in The Netherlands: A general mating advantage to melanics and its consequences. Heredity, 52, (in press).

Brakefield, P. M. \& Willmer, P. G. (1984). The basis of thermal melanism in the ladybird Adalia bipunctata: Differences in reflectance and thermal properties between the morphs. Heredity, (in press).

Casey, T. M. (1981). Behavioural mechanisms of thermoregulation. Insect Thermoregulation (ed. by B. Heinrich), pp. 79-114. John Wiley \& Sons, New York.

Cassie, R. M. (1954). Some uses of probability paper in the analysis of size frequency distributions. Australian Journal of Marine and Freshwater Research, 5, 513-522.

Cena, K. \& Clark, J. A. (1972). Effect of solar radiation on temperatures of working honey bees. Nature New Biology, 236, 222-223.

Cook, L. M. \& Jacobs, Th. M. G. M. (1983). Frequency and selection in the industrial melanic moth Odontoptera bidentata. Heredity, 51, 487-494.

Digby, P. S. B. (1955). Factors affecting the temperature excess of insects in sunshine. Journal of Experimental Biology, 32, 279-298.

Dixon, A. F. G. (1971). The role of intra-specific mechanisms and predation in relating the numbers of the lime aphid, Eucallipterus tiliae L. Oecologia, (Berlin), 8, 179-193.

Dixon, A. F, G. (1972). Control and significance of the seasonal development of colour forms in the sycamore aphid, Drepanosiphum platanoides (Shr). Journal of Animal Ecology, 41, 689-697.

Douglas, M. M. \& Grula, J. W. (1978). Thermoregulatory adaptations allowing ecological range expansion by the pierid butterfly, Nathalis iole Boisduval. Evolution, 32, 776-783.

Edney, E. B. (1971). The body temperatures of tenebrionid beetles in the Namib desert of South Africa. Journal of Experimental Biology, 55, 253-272.

Frazer, J. F. D. \& Rothschild, M. (1960). Defense mechanisms in warningly coloured moths and other insects. Proceedings of the 11th International Congress of Entomology, Wien Verhandlungen B, 3, 249-256.

Hammond, P. M. (1975). Seventeenth century British Coleoptera from the collection of Leonard Plukenet (1642-1706). Entomologist's Gazette, 26, 261-268.

Hill, L. \& Taylor, H. J. (1933). Locusts in sunlight. Nature (London), 132, 276.

Hodek, I. (1973), Biology of Coccinellidae. Academia, Prague.

Lees, D. R. (1981). Industrial melanism: genetic adaptation of animals to air pollution. Genetic Consequences of Man Made Change (Ed. by J. A. Bishop and L. M. Cook), pp. 129-176. Academic Press, London.

Lusis, J. J. (1961). On the biological meaning of colour polymorphism of ladybeetle Adalia bipunctata L. Latvijas Entomologs, 4, 3-29.

Majerus, M. E. N., O'Donald, P. \& Weir, J. (1982). Female mating preference is genetic. Nature (London), 300, 521-523.

Mani, G. S. (1981). Conditions for balanced polymorphism in the presence of differential delay in developmental time. Theoretical Population Biology, 20,363-393.

Mani, G. S. (1982). A theoretical analysis of the morph frequency variation in the peppered moth over England and Wales. Biological Journal of the Linnean Society, 17, 259-267.

Manly, B. F. J. (1973). A note on the estimation of selective values from recaptures of marked animals when selection pressures remain constant over time. Researches on Population Ecology, 14, 151-158.

Muggleton, J. (1978). Selection against the melanic morphs of Adalia bipunctata (two-spot ladybird): a review and some new data. Heredity, 40, 269-280.

Muggleton, J., Lonsdale, D. \& Benham, B. R. (1975). Melanism in Adalia bipunctata L. (Col., Coccinellidae) and its relationship to atmospheric pollution. Journal of Applied Ecology, 12, 451-464.

O'Donald, P. \& Muggleton, J. (1979). Melanic polymorphism in ladybirds maintained by sexual selection. Heredity, 43, 143-148.

Pasteels, J. M., Deroe, C., Tursch, B., Braekman, J. C., Daloze, D. \& Hootele, C. (1973). Distribution et activities des alcaloides defensifs des Coccinellidae. Journal of Insect Physiology, 19, 1771-1784.

Roland, J. (1982). Melanism and diel activity of alpine Colias (Lepidoptera: Pieridae). Oecologia (Berlin), 53, $214-221$.

Scali, V. \& Creed, E. R. (1975). The influence of climate on melanism in the two-spot ladybird, Adalia bipunctata, in central Italy. Transactions of the Royal entomological Society of London, 127, 163-169.

Sokal, R. R. \& Rohlf, F. J. (1981). Biometry (2nd edn). W.H. Freeman \& Co., San Francisco.

Southwood, T. R. E. (1962). Migration of terrestrial arthropods in relation to habitat. Biological Reviews, 37, $171-214$.

Tilling, S. M. (1983), An experimental investigation of the behaviour and mortality of artificial and natural morphs of Cepaea nemoralis (L.). Biological Journal of the Linnean Society, 19, 35-50.

Timofeeff-Ressovsky, N. V. \& Svirezhev, Yu. M. (1966). Adaptation polymorphism in populations of Adalia bipunctata L. Problemy Kibernetike, 16, 136-146. 
Tursch, B., Braekman, J. C., Daloze, D., Hootele, C., Losman, D., Karlsson, R. \& Pasteels, J. M. (1973). Chemical Ecology of Arthropods. VI. Adaline, a novel alkaloid from Adalia bipunctata L. (Coleoptera, Coccinellidae). Tetrahedron Letters, 3, 201-202.

Watt, W. B. (1968). Adaptive significance of pigment polymorphism in Colias butterflies. I. Variation of melanin pigment in relation to thermoregulation. Evolution, 22, 437-458.

Willmer, P. G. \& Unwin, D. M. (1981). Field analyses of insect heat budgets: reflectance, size and heating rates. Oecologia (Berlin), 50, 250-255.

Wratten, S. D. (1973). The effectiveness of the coccinellid beetle, Adalia bipunctata (L.), as a predator of the lime aphid, Eucallipterus tiliae L. Journal of Animal Ecology, 42, 785-802.

(Received 3 May 1983) 